\title{
Spirooxazine Photoisomerization and Relaxation in Polymer Matrices
}

\author{
Maria Larkowska, ${ }^{1}$ Michael Wuebbenhorst, ${ }^{2}$ and Stanislaw Kucharski ${ }^{1}$ \\ ${ }^{1}$ Department of Polymer Engineering and Technology, Wrockaw University of Technology, \\ 50-370 Wrockaw, Poland \\ ${ }^{2}$ Department of Physics and Astronomy, Catholic University Leuven, 3001 Heverlee, Belgium
}

Correspondence should be addressed to Stanislaw Kucharski, stanislaw.kucharski@pwr.wroc.pl

Received 21 March 2011; Accepted 17 June 2011

Academic Editor: Qijin Zhang

Copyright (C) 2011 Maria Larkowska et al. This is an open access article distributed under the Creative Commons Attribution License, which permits unrestricted use, distribution, and reproduction in any medium, provided the original work is properly cited.

$9^{\prime}$-Hydroxy-1,3,3-trimethylspiro[indoline-2,3' [3H]naphtha[2,1-b]-1,4oxazine] (SPO-7OH) was used in studies of photochromic transformations in polymer matrices. Illumination with UV lamp caused opening the spirostructure of the oxazine with formation of open merocyanine species absorbing at ca. $610 \mathrm{~nm}$. The kinetic studies of thermal relaxation of the open form showed that this process can be described with a biexponential function including both photochemical reaction and rheological behaviour of the polymeric environment. Basing on Arrhenius plot of the rate constant ascribed to the photochemical reaction, the activation energy was determined, which was 66.1 and $84.7 \mathrm{~kJ} /$ mole for poly(methyl methacrylate-co-butyl methacrylate) and poly(vinylpyrrolidone) matrix, respectively.

\section{Introduction}

Extensive research has been devoted to gain insight into transformation of photochromic molecules induced by light $[1,2]$. Reversible rearrangement of bistable molecules occurs in photochemical or thermal way. Significantly different molecular states can exist as thermodynamically stable ones. The photoisomers differ in their physical properties such as absorption spectra, refractive indices, dielectric constants, geometrical structure, and oxidation/reduction potential [3]. Interests devoted to photochromic materials have been expanded because of their potential applications in optical devices and memories [4-6].

Among the most important categories of photochromic molecules there are spirocompounds which can induce excellent colouration during irradiation [7-9]. UV light excitation occurs to be relatively strong to cause photocleavage of the $\mathrm{C}-\mathrm{O}$ spirobond of the spirooxazine which leads to the coloured merocyanine; the latter can exist in four isomeric forms [10-12]. The mechanism of the reversible photochromic transformation of spirooxazines involves the photochemical process of ring opening of spirocompound yielding merocyanines and thermal or photochemical relaxation process of closing ring of the merocyanines [13]. The process of reversible isomerization is presented in Figure 1.

Studies on photochromism of spirooxazines have been carried out in various organic solvents as well as in different media, such as polymer matrices, liposomal membranes, monolayers, and bilayer-clay matrices [8]. The lifetimes of excited state of the spiroform and subsequent open form depend on temperature [14-16]. The polarity of polymer matrices is of great importance because of possible interactions between polymer chain and tautomeric form of merocyanine $[12,17]$.

In this paper the main attention was focused on investigation of the temperature influence on reversible isomerization of spirooxazine in polymer matrices. Two polymers with different glass transition temperature and polarity were used as matrices, and concentration of the dye was 30\% by weight. The temperature dependence was controlled by measurement of UV-Vis absorption spectra. It is to mention 


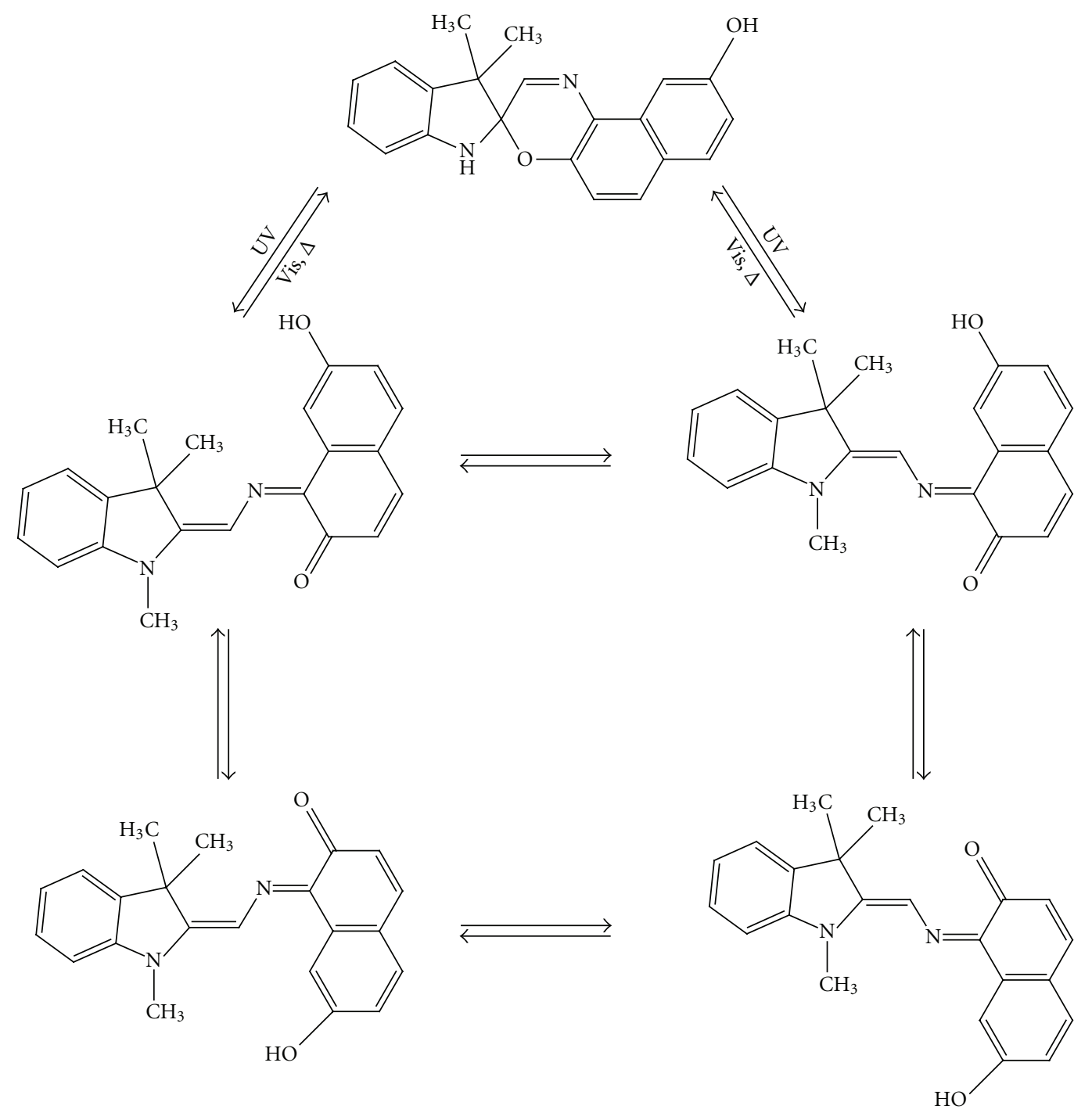

FIGURE 1: Mechanism of photochromic transformations of spirooxazine.

that spirooxazines belong to the photochromic dyes sensitive to UV range of radiation $[10,18,19]$.

\section{Experimental}

2.1. Materials. $9^{\prime}$-Hydroxy-1,3,3-trimethylspiro[indoline-2,3' [3H]naphtha[2,1-b]-1,4oxazine] (SPO-7OH) was synthesized using previously described procedures [18, 19]. 1-Nitrosonaphthalene-2,7-diol (5.28 mmnol, $1.00 \mathrm{~g})$ was dissolved in $100 \mathrm{~mL}$ ethanol. 1,3,3-Trimethyl-2-methyleneindoline $(4.80 \mathrm{mmol}, 0.83 \mathrm{~g})$ was added, and the reaction mixture was refluxed with stirring for 5 hours. The resulting product was purified by silica gel column chromatography using chloroform as an eluent. Yield of SPO-7OH was $41 \%$ (0.68 g).

Poly(methyl methacrylate-co-butyl methacrylate) $(P(M$ $M A-B M A)$ ) and poly(vinylpyrrolidone) (PVP) were purchased from Sigma-Aldrich.

Polymer films containing spirooxazine dye (SPO-7OH) were prepared by spin coating technique. The materials were deposited on glass plates using $6 \%$ solution of $P(M M A-$ $B M A)$ or $3 \%$ solution of $P V P$ in chloroform. The concentration of photochromic compounds ( $\mathrm{SPO}-7 \mathrm{OH})$ in polymers was $30 \%$. The samples were annealed at $423 \mathrm{~K}$ for 8 hours. The thicknesses of polymer films were in the range of 200$400 \mathrm{~nm}$ depending on concentration of polymer solutions. The resulting films were kept in dark before measurement.

2.2. Optical Experiments. UV-Vis spectra were recorded using DT-MINI-2-GS Mikropack UV-VIS-NIR LIGHTSOURCE. The polymer films were irradiated with $365 \mathrm{~nm}$ diode light (type H2A1-H365) providing $25 \mathrm{~mW}$ power. The samples were kept at constant temperature during illumination and thermal relaxation, and the temperature was controlled by DC HEATER SUPPLY.

\section{Results and Discussion}

3.1. Absorption Spectra of Spirooxazine Photochromic System. The measurements of UV-Vis spectra were carried out using 


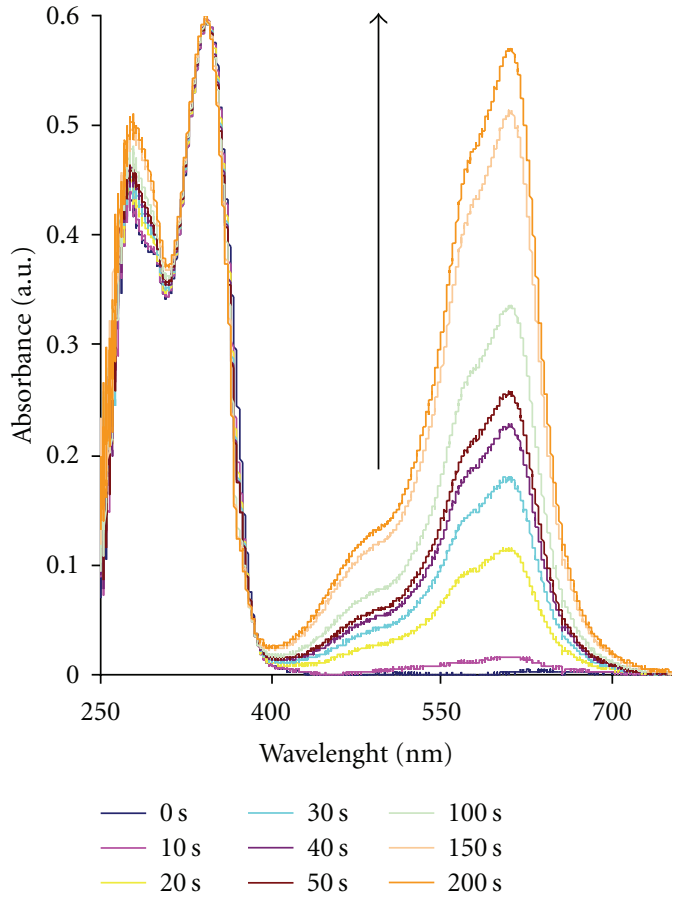

Figure 2: $S P O-7 O H$ in $P(M M A-B M A)$ absorption spectra recorded before UV irradiation and after $200 \mathrm{~s}$ at $303 \mathrm{~K}$.

thin polymer films containing spirooxazine $(\mathrm{SPO}-7 \mathrm{OH})$ on glass plates. The absorption spectra of $\mathrm{SPO}-7 \mathrm{OH}$ in $\mathrm{P}(\mathrm{MMA}-$ $B M A$ ) during illumination with UV diode light and thermal relaxation are presented in Figures 2 and 3, respectively.

Spirooxazine showed maximum absorption peak in the range of ca. 344-350 nm, depending on the polymer matrix. Upon UV light excitation, the spiro-carbon-oxygen $(\mathrm{C}-\mathrm{O})$ bond of colorless ring-closed form breaks and the subsequent isomerization leads to colored ring-open isomers (merocyanine). The maximum absorption peak of merocyanine is located at $610 \mathrm{~nm}$ for $P V P$ and at $613 \mathrm{~nm}$ for $P(M M A-B M A)$ guest host system. The photoisomerization of photochromic materials is reversible. The metastable colored form is changed into ground state colourless form. The route from open to closed form of spirocompound took place as a thermal relaxation process. Influence of temperature on relaxation process was investigated. The measurements were carried out within the range of $303-333 \mathrm{~K}$ in steps of $10 \mathrm{~K}$ under strict temperature control. The UV-Vis spectra were recorded during heating and periodic illumination with $365 \mathrm{~nm}$ diode light. Spectral parameters are presented in Table 1.

3.2. Kinetics of the Thermal Relaxation Process. Kinetic characteristics of thermal relaxation process of SPO-7OH were presented by recording the maximum absorption band decay in two different polymer matrices. The typical curves of absorption growth and relaxation processes are showed in Figure 4.

Several kinetic models are known and used to explain relaxation processes $[14,20,21]$. Biexponential function describes relaxation process sufficiently well, so (1) was

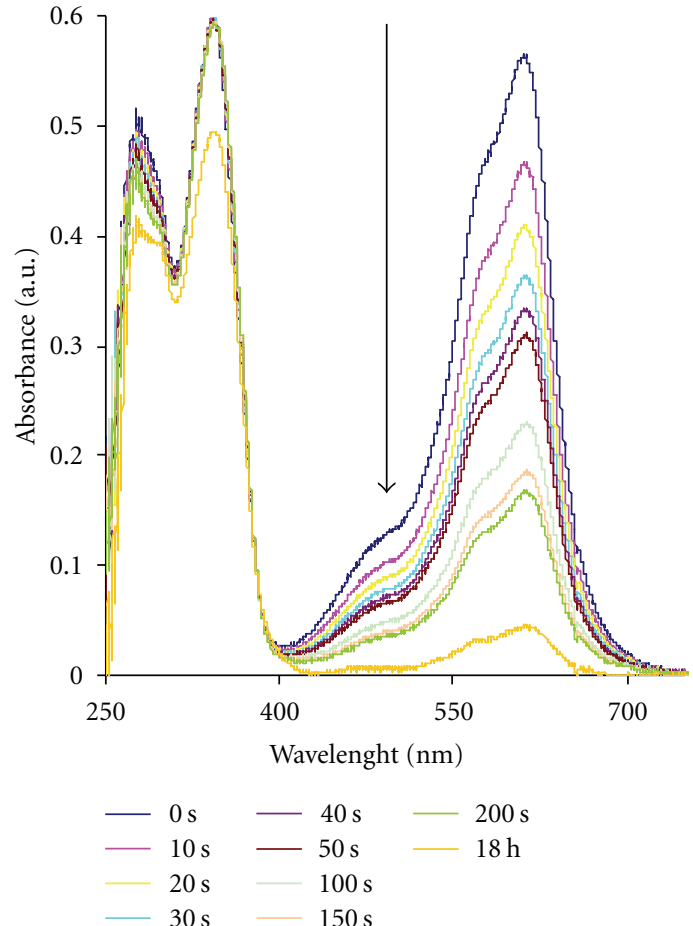

Figure 3: Absorption spectra of $S P O-7 O H$ in $P(M M A-B M A)-$ thermal relaxation process at $303 \mathrm{~K}$.

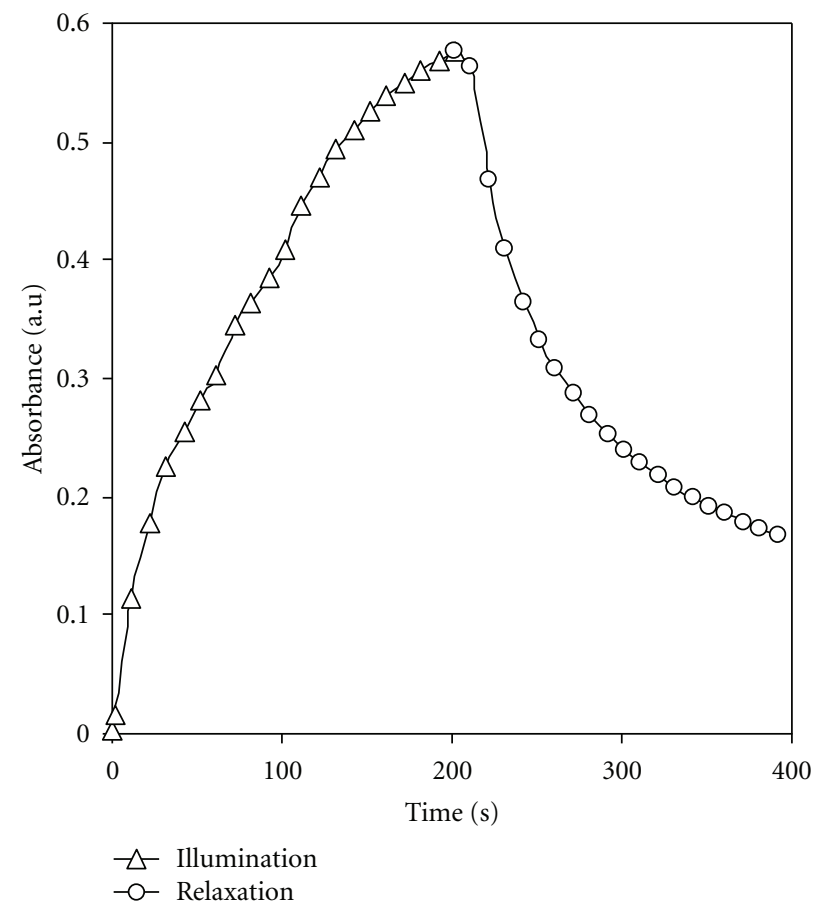

Figure 4: Typical growth and relaxation process of photoinduced absorbance modulation of SPO-7OH in P(MMA-BMA) at $303 \mathrm{~K}$.

chosen to optimize thermal bleaching reaction converting merocyanines to their ground state ring-closed form:

$$
A(t)=a e^{-k_{a} t}+b e^{-k_{b} t}
$$


TABLE 1: Spectral parameters of $S P O-7 O H$ in polymers matrices.

\begin{tabular}{|c|c|c|c|c|c|c|}
\hline Sample & Temperature $(\mathrm{K})$ & $\lambda_{\max }(\mathrm{nm})$ & $A(t)_{i}$ (a.u.) & $t_{i}(\mathrm{~s})$ & $A(t)_{r}$ (a.u.) & $t_{r}(\mathrm{~s})$ \\
\hline SPO-7OH P(MMA-BMA) & 303 & 613 & 0.569 & 200 & 0.167 & 200 \\
\hline SPO-7OH P(MMA-BMA) & 313 & 613 & 0.402 & 200 & 0.078 & 200 \\
\hline SPO-7OH P(MMA-BMA) & 323 & 613 & 0.020 & 200 & 0.015 & 200 \\
\hline SPO-7OH P(MMA-BMA) & 333 & 613 & 0.084 & 200 & 0.000 & 80 \\
\hline SPO-7OH PVP & 303 & 610 & 0.194 & 200 & 0.115 & 200 \\
\hline SPO-7OH PVP & 313 & 610 & 0.170 & 200 & 0.110 & 200 \\
\hline SPO-7OH PVP & 323 & 610 & 0.126 & 200 & 0.083 & 200 \\
\hline SPO-7OH PVP & 333 & 610 & 0.084 & 200 & 0.058 & 200 \\
\hline
\end{tabular}

$A(t)_{i}$ : absorbance of merocyanine measured after time $t_{i}$ during illumination with light;

$A(t)_{r}$ : absorbance of merocyanine measured after time $t_{r}$ during thermal relaxation.

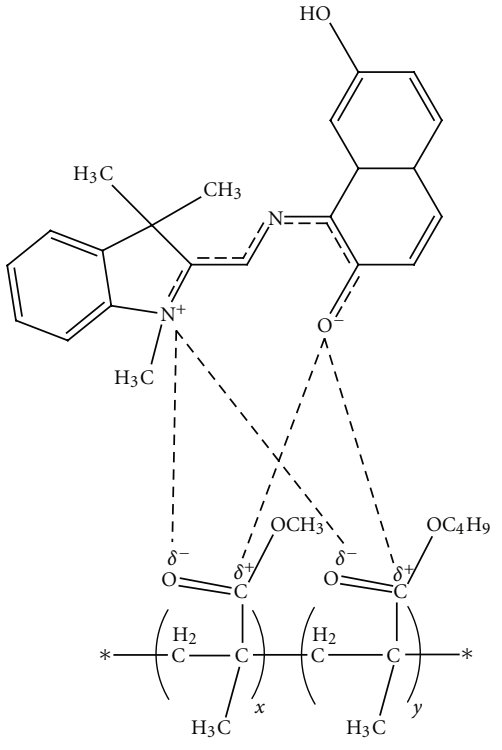

(a)

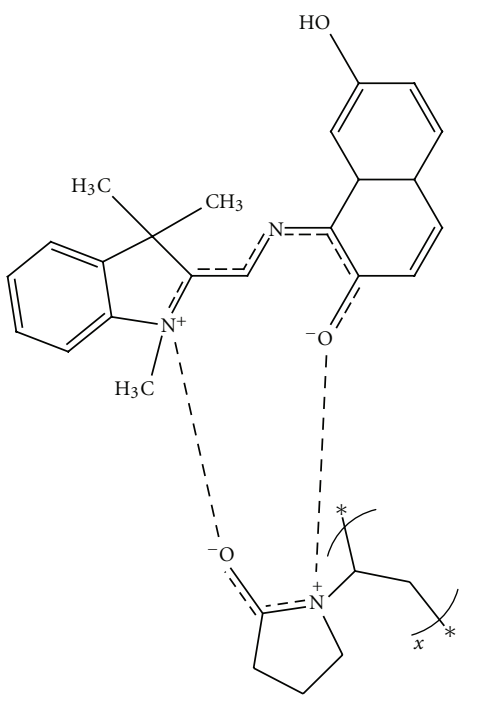

(b)

FIgure 5: The dipole-dipole interaction between merocyanine and side chains of polymers (a) $P(M M A-B M A)$ and (b) $P V P$.

where $A(t)$ is change of absorbance observed at time $t ; k_{a}$ and $k_{b}$ represent the rate constants ascribed to the amplitude of $a$ and $b$, respectively. The first part of (1) is responsible for isomerization of chromophore, and the second part corresponds to material equilibration. The rate constants $k_{a}$ and $k_{b}$ determine the rate of open-closed isomerization and the rate of material reorientation, respectively.

The decay curves were fitted to biexponential decay model using a computer program. This biexponential model fits experimental points into calculated curve very well. All values of the constants are given in Table 2. Along with increase of temperature, there is observed an increase of rate constants and thereby relaxation process is significantly faster at higher temperature. Comparing the rate constants $k_{a}$ and $k_{b}$, it can be noticed that the first process is considerably faster than the second one. This means that the main influence on the rate of relaxation process has openclosed isomerization. However, the suppressing environment relaxation and kind of polymer matrices had a distinct effect that was evidenced by higher values of the rate constants in $P(M M A-B M A)$ versus $P V P$ in guest host system. The polarity of polymer matrices can influence the relaxation rate because of formation of the dipole-dipole interaction between merocyanine and side chains of polymers (Figure 5). The dipolar interactions are significantly stronger in $P V P$ than in $P(M M A-B M A)$. The differences in dipolar interactions of the polymers with merocyanine have a distinct effect on difference in stabilization of merocyanine forms. The relaxation process appeared to be slower when the interactions were more pronounced owing to the presence of nitrogen atoms in PVP polymer.

The Arrhenius equation (2) was used to determine activation energy $\left(E_{a}\right)$ of relaxation process corresponding to the faster step:

$$
\ln \left(k_{a}\right)=\ln k_{0}-\frac{E_{a}}{R} \cdot \frac{1}{T}
$$


TABLE 2: Kinetic parameters for thermal bleaching reaction.

\begin{tabular}{lcccccc}
\hline Sample & Temperature $(\mathrm{K})$ & $a$ & $k_{a}$ & $b$ & $k_{b}$ & $R$ \\
\hline SPO-7OH P(MMA-MBA) & 303 & 0.3798 & 0.0205 & 0.2240 & 0.0017 & 0.996 \\
SPO-7OH P(MMA-MBA) & 313 & 0.1992 & 0.0596 & 0.1930 & 0.0050 & 0.999 \\
SPO-7OH P(MMA-MBA) & 323 & 0.1245 & 0.1013 & 0.0607 & 0.0084 & 0.999 \\
SPO-7OH P(MMA-MBA) & 333 & 0.0467 & 0.2364 & 0.0363 & 0.0434 & 0.997 \\
SPO-7OH PVP & 303 & 0.1026 & 0.0023 & 0.1829 & 0.0001 & 0.999 \\
SPO-7OH PVP & 313 & 0.0364 & 0.0085 & 0.1345 & 0.0004 & 0.999 \\
SPO-7OH PVP & 323 & 0.0260 & 0.0225 & 0.1001 & 0.0011 & 0.999 \\
SPO-7OH PVP & 333 & 0.0116 & 0.0477 & 0.0693 & 0.0011 & 0.999 \\
\hline
\end{tabular}

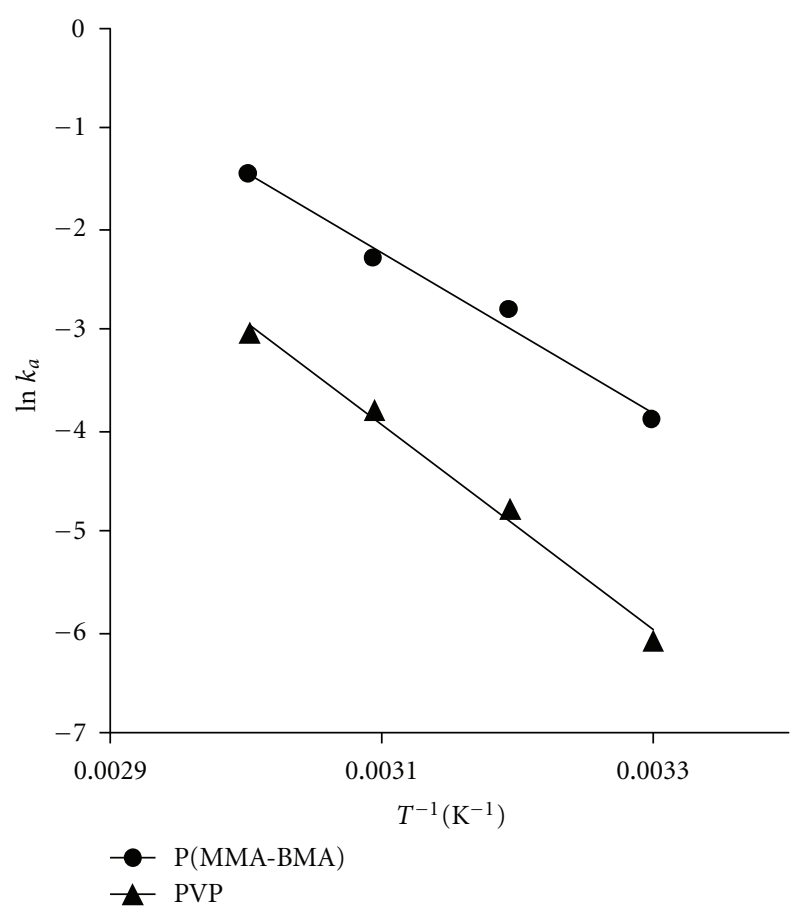

Figure 6: The Arrhenius plots for thermal bleaching of $\mathrm{SPO}-7 \mathrm{OH}$ in polymer matrices.

TABle 3: Activation energy $\left(E_{a}\right)$ and the Arrhenius preexponential factor $\left(k_{0}\right)$ for thermal relaxation process of $S P O-7 O H$ in polymer matrices.

\begin{tabular}{lcc}
\hline Sample & $k_{0}\left[\mathrm{~s}^{-1}\right]$ & $E_{a}\left[\mathrm{~kJ} \cdot \mathrm{mol}^{-1}\right]$ \\
\hline SPO-7OH P(MMA-BMA $)$ & $5.46 \cdot 10^{9}$ & 66.10 \\
SPO-7OH PVP & $1.03 \cdot 10^{12}$ & 84.72 \\
\hline
\end{tabular}

The Arrhenius plots for thermal bleaching of $\mathrm{SPO}-7 \mathrm{OH}$ in polymer matrices were shown in Figure 6 . The calculated values of rate constants $\left(k_{a}\right)$ fit the Arrhenius plots with very good precision, so it was possible to determine values of energy barrier which were presented in Table 3. It can be noticed that activation energy in relaxation process of $S P O-$ $7 O H$ in $P(M M A-B M A)$ is lower than that in $P V P$ which is consistent with expectation.

\section{Conclusions}

The illumination of spirooxazine containing polymer matrix resulted in formation of open merocyanine species absorbing at ca. $610 \mathrm{~nm}$. The reverse process could be described as composed of two stages: first one as a photochemical closing of merocyanine form and the second one as the polymer matrix rheological cooperation response. The Arrhenius plot of the reaction rate constant of the first stage made it possible to determine activation energy of this process that was 66.1 and $84.7 \mathrm{~kJ} /$ mole in poly(methyl methacrylateco-butyl methacrylate) and poly(vinylpyrrolidone) matrix, respectively.

\section{Acknowledgments}

This work was supported by the grant of Chemistry Department of Wrocław University of Technology, Wrocław (Poland), and Catholic University of Leuven (Belgium).

\section{References}

[1] V. Shibaev, A. Bobrovsky, and N. Boiko, "Photoactive liquid crystalline polymer systems with light-controllable structure and optical properties," Progress in Polymer Science, vol. 28, no. 5, pp. 729-836, 2003.

[2] N. Katsonis, M. Lubomska, M. M. Pollard, B. L. Feringa, and P. Rudolf, "Synthetic light-activated molecular switches and motors on surfaces," Progress in Surface Science, vol. 82, no. 7-8, pp. 407-434, 2007.

[3] H. Bousas-Laurent and H. Durr, "Organic photochromism (IUPAC technical report)," Pure and Applied Chemistry, vol. 73, no. 4, pp. 639-665, 2001.

[4] A. Natansohn and P. Rochon, "Photoinduced motions in azocontaining polymers," Chemical Reviews, vol. 102, no. 11, pp. 4139-4176, 2002.

[5] V. Mateev, P. Markovskii, L. Nikolova, and T. Todorov, "Temperature dependence of photoinduced anisotropy in rigid solutions of azo dyes," Journal of Physical Chemistry, vol. 96, no. 7, pp. 3055-3058, 1992.

[6] G. Berkovic, V. Krongauz, and V. Weiss, "Spiropyrans and spirooxazines for memories and switches," Chemical Reviews, vol. 100, no. 5, pp. 1741-1754, 2000.

[7] M. M. Oliveira, M. A. Salvador, P. J. Coelho, and L. M. Carvalho, "New benzopyranocarbazoles: synthesis and photochromic behaviour," Tetrahedron, vol. 61, no. 7, pp. 16811691, 2005. 
[8] G. Favaro, G. Chidichimo, P. Formoso, S. Manfredi, U. Mazzucato, and A. Romani, "Chromatic and dynamic characteristics of some photochromes in the components of bifunctional photochromic and electro-optical devices," Journal of Photochemistry and Photobiology A, vol. 140, no. 3, pp. 229-236, 2001.

[9] V. I. Minkin, "Photo-, thermo-, solvato-, and electrochromic spiroheterocyclic compounds," Chemical Reviews, vol. 104, no. 5, pp. 2751-2776, 2004.

[10] S. Kucharski and E. Ortyl, "Refractive index modulation in the films containing single and dual chromophore system," Polimery, vol. 51, no. 7-8, pp. 555-560, 2006.

[11] S. Kucharski, E. Ortyl, and R. Janik, "Photochromic properties of the polymer films containing single and dual chromophore system," Nonlinear Optics Quantum Optics, vol. 36, no. 3-4, pp. 271-280, 2007.

[12] J. S. Lin, "Interaction between dispersed photochromic compound and polymer matrix," European Polymer Journal, vol. 39, no. 8, pp. 1693-1700, 2003.

[13] N. A. Voloshin, A. V. Metelitsa, J. C. Micheau et al., "Spiropyrans and spirooxazines 1. Synthesis and photochromic properties of $9^{\prime \prime}$-hydroxy- and 9" -alkoxy-substituted spironaphthooxazines," Russian Chemical Bulletin, vol. 52, no. 5, pp. 1172-1181, 2003.

[14] M. Suzuki, T. Asahi, and H. Masuhara, "Temperature dependence of ultrafast photoinduced ring-opening and -closure reactions of spironaphthooxazine in crystalline phase," Journal of Photochemistry and Photobiology A, vol. 178, no. 2-3, pp. 170-176, 2006.

[15] I.-J. Lee, "Thermal reactions of spironaphthooxazine dispersed in polystyrene film at low temperatures," Journal of Photochemistry and Photobiology A, vol. 146, no. 3, pp. 169173, 2002.

[16] S. H. Kim, H. J. Suh, J. Z. Cui, Y. S. Gal, S. H. Jin, and K. Koh, "Crystalline-state photochromism and thermochromism of new spiroxazine," Dyes and Pigments, vol. 53, no. 3, pp. 251256, 2002.

[17] S. Delbaere and G. Vermeersch, "NMR spectroscopy applied to photochromism investigations," Journal of Photochemistry and Photobiology C, vol. 9, no. 2, pp. 61-80, 2008.

[18] S. Benard and P. Yu, "New spiropyrans showing crystallinestate photochromism," Advanced Materials, vol. 12, no. 1, pp. 48-50, 2000.

[19] A. Samat, V. Lokshin, K. Chamontin, D. Levi, G. Pepe, and R. Guglielmetti, "Synthesis and unexpected photochemical behaviour of biphotochromic systems involving spirooxazines and naphthopyrans linked by an ethylenic bridge," Tetrahedron, vol. 57, no. 34, pp. 7349-7359, 2001.

[20] M. Levitus, M. Talhavini, R. M. Negri, T. D. Z. Atvars, and P. F. Aramendia, "Novel kinetic model in amorphous polymers. Spiropyran-merocyanine system revisited," Journal of Physical Chemistry B, vol. 101, no. 39, pp. 7680-7686, 1997.

[21] S. O. Besugliy, A. V. Metelitsa, V. Z. Shirinian, M. M. Krayushkin, D. M. Nikalin, and V. I. Minkin, "Novel photochromic spirocyclic compounds of thienopyrroline series: 2 . Spirooxazines," Journal of Photochemistry and Photobiology A, vol. 206, no. 2-3, pp. 116-123, 2009. 

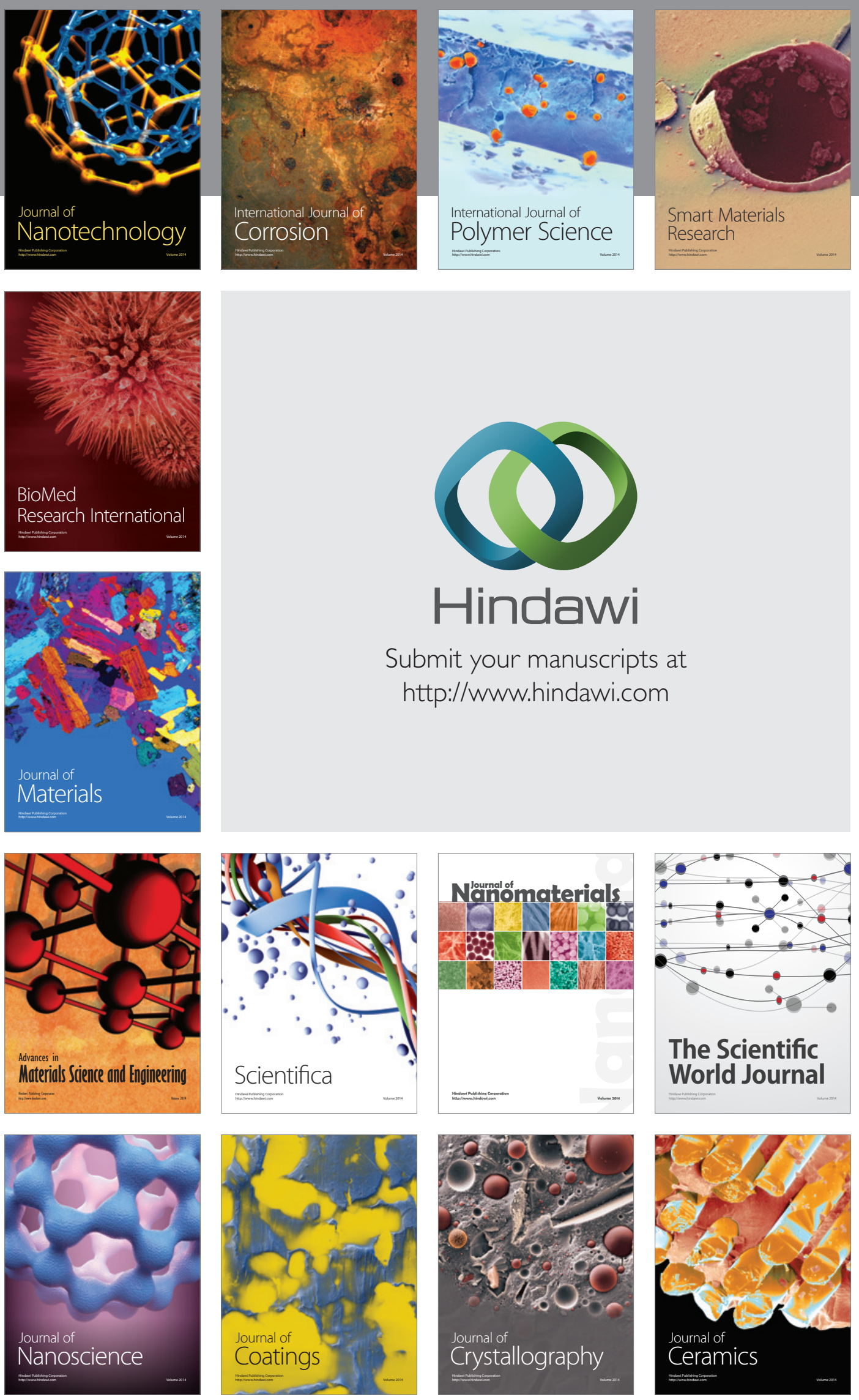

The Scientific World Journal

Submit your manuscripts at

http://www.hindawi.com

\section{World Journal}

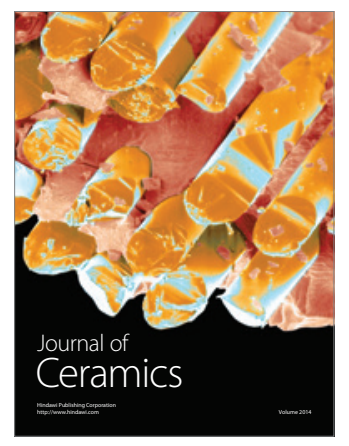

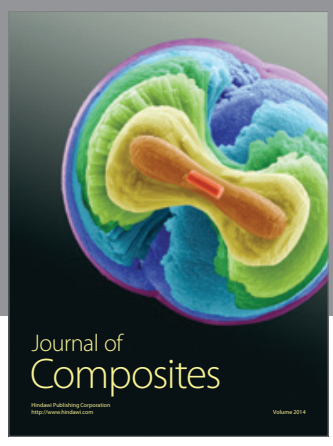
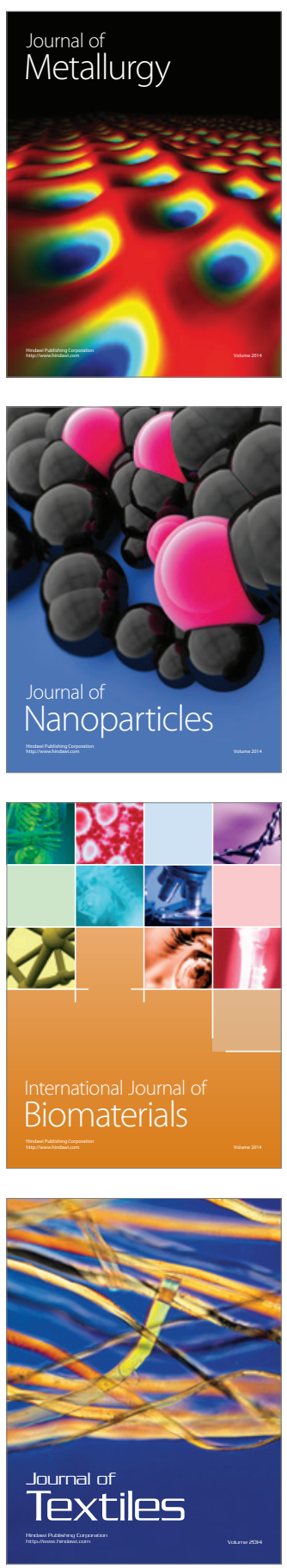